\title{
Completion of a Dislocated Metric Space
}

\author{
P. Sumati Kumari, ${ }^{1}$ I. Ramabhadra Sarma, ${ }^{2}$ J. Madhusudana Rao, $^{3}$ and D. Panthi ${ }^{4}$ \\ ${ }^{1}$ Department of Mathematics, K L University, Vaddeswaram, Andhra Pradesh 522502, India \\ ${ }^{2}$ Department of Mathematics, Acharya Nagarjuna University, Andhra Pradesh 522 510, India \\ ${ }^{3}$ Department of Mathematics, Vijaya College of Engineering, Khammam, Telangana 507 305, India \\ ${ }^{4}$ Department of Mathematics, Nepal Sanskrit University, Valmeeki Campus, Exhibition Road, Kathmandu 44500, Nepal
}

Correspondence should be addressed to P. Sumati Kumari; mumy143143143@gmail.com

Received 26 August 2014; Accepted 4 November 2014

Academic Editor: Kyung Soo Kim

Copyright (C) 2015 P. Sumati Kumari et al. This is an open access article distributed under the Creative Commons Attribution License, which permits unrestricted use, distribution, and reproduction in any medium, provided the original work is properly cited.

We provide a construction for the completion of a dislocated metric space (abbreviated $d$-metric space); we also prove that the completion of the metric associated with a $d$-metric coincides with the metric associated with the completion of the $d$-metric.

\section{Introduction}

Completion of a metric space via Cauchy sequences can be achieved because of certain convergence properties enjoyed by the metric and the property that convergent sequences are Cauchy sequences. Lack of some of these properties in weaker forms of metric spaces comes in the way of completion process in the above lines. In semimetric spaces several new ways of completeness were invented, for example, Cauchy completeness, McAuley notions of strong and weak completeness [1], Moore completeness [2], and so on. Moshokoa [3] introduced the notion of convergence completeness for semimetric spaces and discussed completion on these lines.

For $d$-metric spaces adoption of Van der-Waerdens completion process through Cauchy sequences is possible but is not routine, the difficulty being the mischief created by the isolated points. Here we show how to overcome this problem.

In his study of programming languages, Hitzler [4] associated a metric $d^{\prime}$ with every $d$-metric by defining

$$
d^{\prime}(a, b)= \begin{cases}d(a, b), & \text { if } a \neq b \\ 0, & \text { if } a=b\end{cases}
$$

We establish that the metric associated with the completion of a $d$-metric is the completion of the metric associated with $d$.
We recall [4] where a distance function on a set $X$ is said to be a $d$-metric on $X$ if

(i) $d(x, y)=d(y, x)$;

(ii) $d(x, y)=0 \Rightarrow x=y$;

(iii) $d(x, z) \leq d(x, y)+d(y, z)$ for all $x, y, z$ in $X$.

If $d$ is a $d$-metric on $X$ then $(X, d)$ is called a $d$-metric space. Many authors (see, e.g. [5-9]) have studied fixed point theorems in $d$-metric spaces but topology and topological aspects on this space are discussed by Sarma and Kumari [10].

The class $\mathscr{B}=\left\{V_{\epsilon}(x) / x \in X\right.$ and $\left.\epsilon>0\right\}$ is an open base for the topology $\widetilde{J}_{d}$ induced by $d$, where $V_{\epsilon}(x)=\{y / d(x, y)<$ $\epsilon\} \cup\{x\}$. In what follows whenever we talk about topological properties of a $d$-metric space, we refer to the topology $\widetilde{J}_{d}$.

In [11], the authors highlighted some convergence properties and covers a huge range of implications and nonimplications among them. By using these convergence axioms many authors (see, e.g. [12-15]) have proved fixed point theorems in certain spaces.

The presence of the triangle inequality lends the Haussdorff property for $d$ and some nice properties to $(X, d)$. In particular $(X, d)$ satisfies properties $C_{1}$ through $C_{5}$ :

$$
\begin{aligned}
& C_{1}: \lim d\left(x_{n}, y_{n}\right)=0=\lim d\left(x_{n}, x\right) \Rightarrow \lim d\left(y_{n}, x\right)=0 ; \\
& C_{2}: \lim d\left(x_{n}, x\right)=0=\lim d\left(y_{n}, x\right) \Rightarrow \lim d\left(x_{n}, y_{n}\right)=0 ; \\
& C_{3}: \lim d\left(x_{n}, y_{n}\right)=0=\lim d\left(y_{n}, z_{n}\right) \Rightarrow \lim d\left(x_{n}, z_{n}\right)=
\end{aligned}
$$$$
0 \text {; }
$$ 


$$
\begin{aligned}
& C_{4}: \lim d\left(x_{n}, x\right)=0 \Rightarrow \lim d\left(x_{n}, y\right)=d(x, y) \\
& C_{5}: \lim d\left(x_{n}, x\right)=\lim d\left(x_{n}, y\right)=0 \Rightarrow x=y \text {; for all } \\
& \quad x, y \in X
\end{aligned}
$$

Above mentioned convergence axioms can be found in [11]. If the triangular inequality is deleted from the axioms on $d$ then it is difficult to define the concept of completion of the resulting distance space. In such an amorphous space, even constant sequences may fail to converge. This and related difficulties compel us to retain the triangle inequality in the discussion of completeness.

Definition 1. Let $(X, d)$ and $\left(Y, d^{\prime}\right)$ be distance spaces. A map $f: X \rightarrow Y$ is called an isodistance if for any $x, y \in X$ one has $d\{f(x), f(y)\}=d^{\prime}(x, y)$.

\section{Completion}

In what follows, $d$ is a $d$-metric on a nonempty set $X$. A complete $d$-metric space is a $d$-metric space in which every Cauchy sequence converges. "Cauchy sequences" in $d$-metric spaces are defined exactly as in metric spaces.

Lemma 2. $x$ is an isolated point of $X$ if and only if $X=x$ or $\inf _{y \neq x} d(x, y)>0$.

Proof. Suppose $x$ is an isolated point of $X$. Then there exists $r>0$ such that $y \neq x \Rightarrow d(x, y)>r \Rightarrow X=\{x\}$ or $\inf _{y \neq x} d(x, y) \geq r>0$. Conversely suppose $X=\{x\}$ or $\inf _{y \neq x} d(x, y)>0$. If $X=\{x\}$, then clearly $x$ is an isolated point of $X$. If $X \neq\{x\}$, then $\inf _{y \neq x} d(x, y)=r>0$ which implies that $d(x, y) \geq r>r / 2$ for all $y \neq x$. Hence $x$ is an isolated point of $X$.

Corollary 3. If $d(x, x)>0$, then $x$ is an isolated point of $X$.

Proof. If $y \neq x$, then $d(x, x) \leq d(x, y)+d(y, x)=2 d(x, y)$ and so $(1 / 2) d(x, x) \leq d(x, y)$ for all $y$ in $X$. So $X=\{x\}$ or $\inf _{y \neq x} d(x, y) \geq(1 / 2) d(x, x)>0$.

Theorem 4. Let $(X, d)$ be a d-metric space. Then there exists a complete $d$-metric space $\left(X^{*}, d^{*}\right)$ and an isodistance $T$ : $(X, d) \rightarrow\left(X^{*}, d^{*}\right)$ such that $T(X)$ is dense in $X^{*}$.

Proof. Let $I$ be the collection of isolated points of $X$ and let $J=X-I$. Let $\bar{I}$ be the collection of sequences in $X$ which are ultimately a constant element lying in $I$ and $\bar{J}$ denote the class of Cauchy sequences in $J$. We define relations $R_{I}$ and $R_{J}$, respectively, on $\bar{I}$ and $\bar{J}$ as follows.

If $\left(x_{n}\right)\left(y_{n}\right)$ are sequences in $\bar{I}$ then $\left(x_{n}\right) R_{I}\left(y_{n}\right)$ iff the ultimately constant value of $\left(x_{n}\right)$ coincides with that of $\left(y_{n}\right)$.

If $\left(x_{n}\right)\left(y_{n}\right)$ are sequences in $\bar{J}$ then $\left(x_{n}\right) R_{J}\left(y_{n}\right)$ iff $\lim _{n \rightarrow \infty} d\left(x_{n}, y_{n}\right)=0$. Clearly $R_{I}$ is an equivalence relation. We verify that $R_{J}$ is an equivalence relation. Suppose $\left(x_{n}\right) \in \bar{J}$ and $\epsilon>0$. Since $\left(x_{n}\right)$ is a Cauchy sequence in $J, d\left(x_{n}, x_{n}\right)=0$ and hence $R_{J}$ is reflexive.

Suppose $\left(x_{n}\right) R_{J}\left(y_{n}\right)$ for $\left(x_{n}\right),\left(y_{n}\right) \in \bar{J}$. Then $\lim _{n \rightarrow \infty} d\left(x_{n}\right.$, $\left.y_{n}\right)=\lim _{n \rightarrow \infty} d\left(y_{n}, x_{n}\right)=0$. Hence $R_{J}$ is symmetric.
If $\left(x_{n}\right),\left(y_{n}\right),\left(z_{n}\right) \in \bar{J},\left(x_{n}\right) R_{J}\left(y_{n}\right)$ and $\left(y_{n}\right) R_{J}\left(z_{n}\right)$. If $\epsilon>0$, then there exists an integer $n_{1}$ such that $d\left(x_{n}, y_{n}\right)<\epsilon / 2$ and $d\left(y_{n}, z_{n}\right)<\epsilon / 2$, if $n>n_{1}$. Consider

$$
d\left(x_{n}, z_{n}\right) \leq d\left(x_{n}, y_{n}\right)+d\left(y_{n}, z_{n}\right)<\frac{\epsilon}{2}+\frac{\epsilon}{2}=\epsilon \quad \text { if } n>n_{1} .
$$

This proves that $R_{J}$ is transitive and hence an equivalence relation. Let $\bar{X}=\bar{I} \cup \bar{J}$. Then $\sim=R_{I} \cup R_{J}$ is an equivalence relation on $\bar{X}$.

Let $X^{*}$ denote $\bar{X} / \sim$. If $\left(x_{n}\right) \in \bar{X},\left[\left(x_{n}\right)\right]$ denotes the equivalence class in $X^{*}$ containing the sequence $\left(x_{n}\right)$.

If $x \in X$ let $(x)$ be the constant sequence $\left(x_{n}\right)$ where $x_{n}=$ $x, \forall n$ and $\widehat{x}=[(x)]$, the equivalence class containing $(x)$.

If $\left(x_{n}\right) \in \bar{J},\left(y_{n}\right) \in \bar{J}$, it follows from the triangle inequality that $\left|d\left(x_{n}, y_{n}\right)-d\left(x_{m}, y_{m}\right)\right| \leq d\left(x_{n}, x_{m}\right)+d\left(y_{n}, y_{m}\right)$. Since $\left(x_{n}\right),\left(y_{n}\right)$ are Cauchy sequences, given that $\epsilon>0$, there exists a positive integer $n_{0}$ such that $d\left(x_{n}, x_{m}\right)<\epsilon / 2$ and $d\left(y_{n}, y_{m}\right)<\epsilon / 2$ for all $n, m \geq n_{0}$.

This implies that $\left|d\left(x_{n}, y_{n}\right)-d\left(x_{m}, y_{m}\right)\right|<\epsilon$ proving that $\left(d\left(x_{n}, y_{n}\right)\right)$ is a Cauchy sequence of real numbers. By the completeness of $R$ this sequence converges. The definition of $R_{J}$ makes it obvious that $\lim _{n \rightarrow \infty} d\left(x_{n}, y_{n}\right)$ is independent of the choice of the representative sequences $\left(x_{n}\right),\left(y_{n}\right)$, respectively, from the classes $\left[\left(x_{n}\right)\right],\left[\left(y_{n}\right)\right]$.

We can prove similarly if $x \in X$ and $\left(y_{n}\right) \in \bar{J},\left(z_{n}\right) \in$ $\bar{J}, \lim d\left(x, y_{n}\right), \lim d\left(x, z_{n}\right)$ exists and or equal. Provided $\left(y_{n}\right)$ and $\left(z_{n}\right)$ belong to the same equivalence class.

We define $d^{*}: X^{*} \times X^{*} \rightarrow[0, \infty)$ as follows:

$d^{*}\left(\left[\left(x_{n}\right)\right],\left[\left(y_{n}\right)\right]\right)=d(x, y)$ if $\left(x_{n}\right),\left(y_{n}\right) \in \bar{I}$ and $x, y$ are, respectively, the ultimately constant terms of $\left(x_{n}\right),\left(y_{n}\right)$

$d^{*}\left(\left[\left(x_{n}\right)\right],\left[\left(y_{n}\right)\right]\right)=\lim _{n \rightarrow \infty} d\left(x, y_{n}\right)$ if $\left(x_{n}\right) \in \bar{I}$, $\left(y_{n}\right) \in \bar{J}$ and $x_{n}=x$ eventually.

If $\left(x_{n}\right) \in \bar{J},\left(y_{n}\right) \in \bar{I}$, then define $d^{*}\left(\left[\left(x_{n}\right)\right],\left[\left(y_{n}\right)\right]\right)=$ $d^{*}\left(\left[\left(Y_{n}\right)\right],\left[\left(X_{n}\right)\right]\right)$.

If $\left(x_{n}\right) \in \bar{J},\left(y_{n}\right) \in \bar{J}$, then define $d^{*}\left(\left[\left(x_{n}\right)\right],\left[\left(y_{n}\right)\right]\right)=$ $\lim _{n \rightarrow \infty} d\left(x_{n}, y_{n}\right)$.

Verification That $d^{*}$ Is a d-Metric on $X^{*}$. Clearly $d^{*}\left(x^{*}, y^{*}\right) \geq$ 0 and $d^{*}\left(x^{*}, y^{*}\right)=d^{*}\left(y^{*}, x^{*}\right)$ for $x^{*}, y^{*} \in X^{*}$.

Suppose $d^{*}\left(x^{*}, y^{*}\right)=0$. Let $\left(x_{n}\right) \in x^{*}$ and $\left(y_{n}\right) \in y^{*}$. We first see that $\left(x_{n}\right),\left(y_{n}\right)$ either are both in $\bar{I}$ or are both in $\bar{J}$.

Suppose, on the contrary, $\left(x_{n}\right) \in \bar{I}$ and $\left(y_{n}\right) \in \bar{J}$. Let $x$ be the ultimately constant value of $\left(x_{n}\right)$. Consider

$$
\begin{aligned}
& 0 \leq d(x, x) \leq 2 d\left(x, y_{n}\right) \quad \forall n, \\
& \Longrightarrow 0=d^{*}\left(x^{*}, y^{*}\right)=\lim _{n \rightarrow \infty} d\left(x, y_{n}\right) .
\end{aligned}
$$

Hence $0 \leq d(x, x) \leq \lim _{n \rightarrow \infty} 2 d\left(x, y_{n}\right)=0$, contrary to the fact that $x \in I$.

Suppose $x^{*}, y^{*} \in \bar{I},\left(x_{n}\right) \in x^{*}$, and $\left(y_{n}\right) \in y^{*}$ with $a, b$ the ultimately constant values of $\left(x_{n}\right)$ and $\left(y_{n}\right)$, respectively.

Then $d^{*}\left(x^{*}, y^{*}\right)=0 \Rightarrow d(a, b)=0 \Rightarrow a=b \Rightarrow\left(x_{n}\right) \sim$ $\left(y_{n}\right) \Rightarrow x^{*}=y^{*}$. 
Suppose $x^{*}, y^{*} \in \bar{J},\left(x_{n}\right) \in x^{*}$ and $\left(y_{n}\right) \in y^{*}$. Consider

$$
\begin{aligned}
& d^{*}\left(x^{*}, y^{*}\right)=0 \Longrightarrow \lim _{n \rightarrow \infty} d\left(x_{n}, y_{n}\right)=0 \\
& \Longrightarrow\left(x_{n}\right) \sim\left(y_{n}\right) \\
& \Longrightarrow x^{*}=y^{*} .
\end{aligned}
$$

Verification of the triangular inequality is routine.

Embedding of $X$ in $X^{*}$. Define $T: X \rightarrow X^{*}$ by $T(x)=\hat{x}$. It is clear that $T$ is an isodistance. We now verify that $T(x)$ is dense in $X^{*}$. Let $\left[\left(x_{n}\right)\right] \in X^{*}$ and $\epsilon>0$.

Case (i) $\left(\left(x_{n}\right) \in \bar{I}\right)$. In this case let " $a$ " be the ultimately constant value of $\left(x_{n}\right)$.

Then by the definition of $T, \hat{a}=\left[\left(x_{n}\right)\right] \in T(X)$.

Then $\widehat{a}=\left[\left(x_{n}\right)\right]$. Thus $\left[\left(x_{n}\right)\right] \in T(X)$ in this case.

Case (ii) $\left(\left(x_{n}\right) \in \bar{J}\right)$. There exists a positive integer $n_{0}$ such that $d\left(x_{n}, x_{m}\right)<\epsilon$ if $n, m \geq n_{0}$. Let $x_{n_{0}}=a$. Then since $a \in$ $J, d(a, a)=0$,

$$
d^{*}([(x)], \widehat{a})=\lim _{n \rightarrow \infty} d\left(x_{n}, a\right) \leq \epsilon .
$$

Hence $T(X)$ is dense in $X^{*}$.

$\left(X^{*}, d^{*}\right)$ Is Complete. Let $\left(x_{n}^{*}\right)$ be a Cauchy sequence in $X^{*}$, and $\epsilon>0$. There exists $n_{0}$ such that $n \geq m \geq n_{0}$ implies $d^{*}\left(x_{n}^{*}, x_{m}^{*}\right)<\epsilon / 3$.

There is no harm in assuming that $n_{0}>\epsilon / 3$. Since $T(X)$ is dense in $X^{*}$, for each positive integer $n$, there exists $z_{n}$ in $X$ such that $d\left(x_{n}^{*}, \widehat{z}_{n}\right)<1 / n$.

Hence

$$
\begin{aligned}
d^{*}\left(\widehat{z}_{n}, \widehat{z}_{m}\right) & \leq d^{*}\left(\widehat{z}_{n}, x_{n}^{*}\right)+d^{*}\left(x_{n}^{*}, x_{m}^{*}\right)+d^{*}\left(x_{m}^{*}, \widehat{z}_{m}\right) \\
& <\frac{1}{n}+\frac{1}{m}+\frac{\epsilon}{3} \\
& <\frac{\epsilon}{3}+\frac{\epsilon}{3}+\frac{\epsilon}{3}=\epsilon \quad \text { if } n, m \geq n_{0} .
\end{aligned}
$$

Hence $\left(\widehat{z}_{n}\right)$ is a Cauchy sequence in $T(X)$. Since $T$ is an isodistance, $\left(z_{n}\right)$ is a Cauchy sequence in $X$.

Moreover, $d\left(z_{n}, z_{m}\right)=d^{*}\left(\widehat{z}_{n}, \widehat{z}_{m}\right)<\epsilon$, if $n \geq m \geq n_{0}$.

Let $z^{*}$ denote $\left[\left(z_{n}\right)\right]$, by the triangle inequality:

$$
\begin{aligned}
& <(1 / n)+\lim _{m} d\left(z_{n}, z_{m}\right)<(2 \epsilon / 3)<\epsilon \text { for } n \geq n_{0} ; \\
& d^{*}\left(x_{n}^{*}, z^{*}\right) \leq d^{*}\left(x_{n}^{*}, \widehat{z}_{n}\right)+d^{*}\left(\widehat{z}_{n}, z^{*}\right) \\
& \Rightarrow \lim _{m} d^{*}\left(x_{n}^{*}, z^{*}\right)=0 \text { proving that }\left(X^{*}, d^{*}\right) \text { is com- } \\
& \text { plete. }
\end{aligned}
$$

Definition 5. Let $(X, d)$ and $\left(X_{1}, d_{1}\right)$ be $d$-metric spaces. $\left(X_{1}, d_{1}\right)$ is said to be a completion of $(X, d)$ if

(i) $\left(X_{1}, d_{1}\right)$ is complete;

(ii) there is an isodistance $T:(X, d) \rightarrow\left(X_{1}, d_{1}\right)$ such that $T(X)$ is dense in $X_{1}$.
Note. If $(X, d)$ is a complete metric space then its completion is $(X, d)$ itself.

Lemma 6. Let $(X, d)$ be a d-metric space and let $\left(X_{1}, d_{1}\right)$ be a completion of $(X, d)$. Let $T: X \rightarrow X_{1}$ be isodistance embedding $X$ in $X_{1}$ with $T(X)$ dense in $X_{1}$. Then a point $y$ of $X_{1}$ is an isolated point if and only if $y=T(X)$ for some isolated point $x$ of $X_{1}$.

Proof. Suppose $y$ is an isolated point of $X_{1}$. If $y$ is not in $T(X)$, then since $T(X)$ is dense in $X_{1}$, there exists a sequence $T\left(x_{n}\right)$ in $T(X)$ such that $\lim _{n \rightarrow \infty} d\left(T\left(x_{n}\right), y\right)=0$.

By Lemma 2, it follows that $y$ is not an isolated point of $X_{1}$, a contradiction so that $y=T(X)$ for some $x \in X$. Hence $T x$ is an isolated point of $X_{1}$ and hence that of $T(X)$. Since $X$ and $T(X)$ are isometric, $x$ is an isolated point of $X$.

Conversely, suppose $x$ is an isolated point of $X$. If $T(X)$ is not an isolated point of $X_{1}$, then for each positive integer $k$, there exists $x_{k}$ in $X_{1}$ such that $0<d_{1}\left(x_{k}, T(x)\right) \leq 1 / 2 k$. Since $x_{k} \in X_{1}$, either $x_{k} \in T(X)$ or there exists $y_{n}$ in $T(X)$ such that $0<d_{1}\left(\left(y_{k}\right), x_{k}\right)<d_{1}\left(x_{k}, T(x)\right)$.

Now

$$
\begin{aligned}
0<d_{1}\left(y_{k}, T(x)\right) & \leq d_{1}\left(\left(y_{k}\right), x_{k}\right)+d_{1}\left(x_{k}, T(x)\right) \\
& \leq \frac{1}{2 k}+\frac{1}{2 k}=\frac{1}{k} .
\end{aligned}
$$

Also $y_{k} \neq x$ since $d_{1}\left(\left(y_{k}\right), x_{k}\right)<d_{1}\left(x_{k}, T(x)\right)$.

Hence $0<d_{1}\left(y_{k}, T(x)\right)<1 / k$ which, by Lemma 2 , contradicts the fact that $T(x)$ is an isolated point of $T(X)$.

Theorem 7. Let $(X, d)$ be a $d$-metric space, $\left(X_{1}, d_{1}\right)$ and $\left(X_{2}, d_{2}\right)$ completion of $(X, d)$, and $T_{i}:(X, d) \rightarrow\left(X_{i}, d_{i}\right)(i=$ $1,2)$ isometrics such that $T_{i}(x)$ is dense in $X_{i}$. Then there exists an isodistance $T:\left(X_{1}, d_{1}\right) \stackrel{\text { on to }}{\longrightarrow}\left(X_{2}, d_{2}\right)$ such that following diagram is commutative.

Proof. Consider the following:

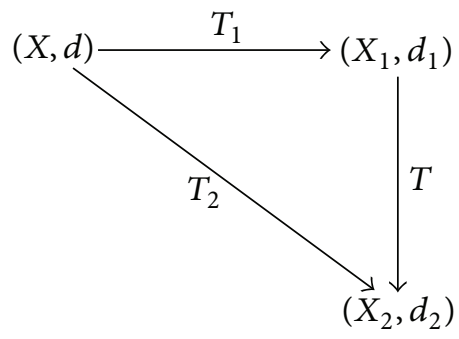

Definition of T. If $x \in X_{1}$ and $x$ is an isolated point of $X_{1}$, then $T_{1}^{-1}(x)$ is an isolated point of $X$; hence $T_{2}\left(T_{1}^{-1}(x)\right)$ is an isolated point of $X_{2}$.

Define $T(x)=T_{2}\left(T_{1}^{-1}(x)\right)$. If $x \in X_{1}$ and is not an isolated point, there exists a sequence $\left(z_{n}\right)$ in $X$ such that $\left\{T_{1} z_{n}\right\}$ converges to $x$ in $\left(X_{1}, d_{1}\right)$.

Since $T_{1}$ is an isodistance and $\left\{T_{1} z_{n}\right\}$ is convergent and hence a Cauchy sequence, it follows that $\left\{z_{n}\right\}$ is a Cauchy sequence in $X$. Since $T_{2}$ is an isodistance and $\left\{z_{n}\right\}$ is a Cauchy 
sequence, it follows that $\left\{T_{2} z_{n}\right\}$ is a Cauchy sequence in $\left(X_{2}, d_{2}\right)$. Since $\left(X_{2}, d_{2}\right)$ is complete, there exists $z \in X_{2}$ such that $\lim d_{2}\left(T_{2} z_{n}, z\right)=0$. Clearly this $z$ is independent of the choice of the sequence $\left\{z_{n}\right\}$ in $X$.

Define $T(x)=z$. Clearly $T T_{1}=T_{2}$ and bijection.

$T$ Is an Isodistance. If $x, y \in X, T\left(T_{1}(x)\right)=T_{2}(x)$ and $T\left(T_{1}(y)\right)=T_{2}(y)$.

So $d_{2}\left(T\left(T_{1}(x)\right), T\left(T_{1}(y)\right)\right)=d_{2}\left(\left(T_{2}(x)\right), T_{2}(y)\right)=d_{2}(x$, $y)=d_{1}\left(\left(T_{1}(x)\right), T_{1}(y)\right)$.

If $x, y \in X_{1}-X$ and $x=\lim T_{1} x_{n}, y=\lim T_{1} y_{n}$ where $x_{n}, y_{n} \in X$, then

$$
\begin{aligned}
d_{2}(T x, T y) & =d_{2}\left(\lim T_{2} x_{n}, \lim T_{2} y_{n}\right) \\
& =\lim d_{2}\left(\lim T_{2} x_{n}, \lim T_{2} y_{n}\right) \\
& =\lim d\left(x_{n}, y_{n}\right) \\
& =d_{1}\left(\lim T_{1} x_{n}, \lim T_{1} y_{n}\right) \\
& =d_{1}(x, y) .
\end{aligned}
$$

The arguments for the cases when $x \in X_{1}-X$ and $y \in X$ or $x \in X$ and $y \in X_{1}-X$ are similar. Hence $T$ is an isodistance. Interchanging the places of $X_{1}$ and $X_{2}$, we get in a similar way an isodistance $S: X_{2} \rightarrow X_{1}$ such that $S T_{2}=T_{1}$.

Since $S T_{2}=T_{1}$ and $T T_{1}=T_{2}$, we have $T S T_{2}=T T_{1}$ and $S T T_{1}=S T_{2}=T_{1}$.

Since $T(X)$ is dense in $X_{1}$ and $T_{2}(x)$ in $X_{2}$, we get $T S=$ identity on $X_{1}$ and $S T$ is identity on $X_{2}$.

Hence $S$ and $T$ are bijections.

\section{Completion of the Metric Associated with a $d$-Metric}

If $d$ is a $d$-metric on $X$ then $d^{\prime}$ is a metric on $X$ if $d^{\prime}$ is defined by $d^{\prime}(x, y)=d(x, y)$ when $x \neq y$ and $d^{\prime}(x, y)=0$ for all $x, y$ in $X$.

Suppose $(\bar{X}, \bar{d})$ is the completion of $(X, d)$; then $\bar{d}$ gives rise to a metric $\bar{d}^{\prime}$ defined by $\bar{d}^{\prime}(x, y)=\bar{d}(x, y)$ for all $x, y \in$ $\bar{X}$ and $\bar{d}(x, x)=0$ for all $x, y \in \bar{X}$.

Also, the metric space $\left(X, d^{\prime}\right)$ has a metric space $\left(X_{0}, d_{0}\right)$ as its completion. In this section, we prove that the metric spaces $\left(\bar{X}, \bar{d}^{\prime}\right)$ and $\left(X_{0}, d_{0}\right)$ are isometric.

Definition 8. Let $X, d$ be a $d$-metric space. Define $\rho$ on $X \times X$ by

$$
\rho(x, y)= \begin{cases}d(x, y), & \text { if } x \neq y \\ 0, & \text { if } x=y .\end{cases}
$$

d.

$\rho$ is a metric on $X$ and is called the metric associated with

Clearly $0 \leq \rho(x, y) \leq d(x, y) \forall x, y$ and $d(x, x) \leq$ $2 \rho(x, y)$ whenever $x \neq y$. If $s \in\{\rho, d\}, r>0$ and $x \in X$.

Write $\mathscr{B}_{r}^{s}(x)=\{y / s(x, y)<r\}$. Then $\mathscr{B}_{r}^{\rho}(x)=\mathscr{B}_{r}^{d}(x) \cup$ $\{x\}$ and $\mathscr{V}_{r}^{s}(x)=\mathscr{B}_{r}^{s}(x) \cup\{x\}$.

The collection $\left\{\mathscr{V}_{r}^{d}(x) / x \in X, r>0\right\}$ and $\mathscr{V}_{r}^{\rho}(x)=$ $\left\{\mathscr{V}_{r}^{\rho}(x) / x \in X, r>0\right\}$ generate the same topology on $X$.
However, convergent sequences in $X$ are not necessarily the same since constant sequences are convergent sequences with respect to $\rho$, while this holds with respect to $d$ for $x$ with $d(x, x)=0$ only.

Existence of points with positive self-distance leads to unpleasantness in the extension of the concept of continuity in metric spaces as well. This is evident from the following.

Example 9. Let $d$ be a $d$-metric on a set $X$ which is not a metric. So that the set $A=\{x / d(x, x) \neq 0\}$ is nonempty. If $\rho$ is a metric associated with $d$ then the identity map $i:(X, \rho) \rightarrow$ $(X, d)$ is continuous in the usual sense. But if $x \in A$, the constant sequence $(x)$ converges in $(X, \rho)$ while it does not converge in $(X, d)$.

If $(X, d),(Y, \rho)$ we call $f: X \rightarrow Y$ sequentially $d$ continuous if $\lim d\left(x_{n}, x\right)=0 \Rightarrow \lim \rho\left(f\left(x_{n}\right), f(x)\right)=0$.

If $s \in\{\rho, d\}$ and $\left\{x_{n}\right\}$ is a sequence in $X$, we say that $X$ is $s$-Cauchy sequence or simply $s$-Cauchy if $\left\{x_{n}\right\}$ is a Cauchy sequence in $(X, s)$.

Proposition 10. $\lim \rho\left(x_{n}, x\right)=0 \Leftrightarrow$ either

(i) $x_{n}=x$ eventually or

(ii) $\left(x_{n}\right)$ can be split into subsequences $\left(y_{n}\right)$ and $\left(z_{n}\right)$ where $y_{n}=x$ for every $n, z_{n} \neq x$ for any $n$ and $\lim d\left(z_{n}, x\right)=$ 0 .

Proof. Routine.

Proposition 11. If a sequence $\left(x_{n}\right)$ in $X$ is $d$-Cauchy then $\left(x_{n}\right)$ is $\rho$-Cauchy. Conversely if $\left(x_{n}\right)$ is $\rho$-Cauchy and is not eventually constant, then $\left(x_{n}\right)$ is $d$-Cauchy.

Proof. Since $0 \leq \rho\left(x_{n}, x_{m}\right) \leq d\left(x_{n}, x_{m}\right), d$-Cauchy $\Rightarrow \rho$ Cauchy.

Conversely suppose that $\left(x_{n}\right)$ is $\rho$-Cauchy, given $\epsilon>$ $0 \exists \mathscr{N}(\epsilon)$ such that $\rho\left(x_{n}, x_{m}\right)<\epsilon$ if $n \geq \mathcal{N}(\epsilon)$ and $m \geq \mathscr{N}(\epsilon)$. So if $m \geq \mathcal{N}(\epsilon), n \geq \mathcal{N}(\epsilon)$, and $x_{n} \neq x_{m}$, then $d\left(x_{m}, x_{n}\right)<\epsilon$.

Since $\left(x_{n}\right)$ is not eventually constant and $n \geq \mathcal{N}(\epsilon)$, there exists $m \geq \mathscr{N}(\epsilon)$ such that $x_{m} \neq x_{n}$. Then

$$
\begin{aligned}
d\left(x_{n}, x_{n}\right) & \leq d\left(x_{n}, x_{m}\right) d\left(x_{m}, x_{n}\right) \\
& =2 d\left(x_{m}, x_{n}\right) \\
& =2 d\left(x_{n}, x_{n}\right) \\
& <2 \epsilon .
\end{aligned}
$$

Thus if $\left(x_{n}\right)$ is not eventually constant then for all $n \geq \mathcal{N}(\epsilon)$ and $m \geq \mathcal{N}(\epsilon), d\left(x_{n}, x_{m}\right)<2 \epsilon$. Hence $\left(x_{n}\right)$ is $d$-Cauchy.

Example 12. Let $X=(0, \infty)$ and $d(x, y)=x+y$; then

$$
\rho(x, y)= \begin{cases}x+y, & \text { if } x \neq y \\ 0, & \text { if } x=y .\end{cases}
$$

If $\left(x_{n}\right)$ is any eventually nonconstant sequence in $(0, \infty)$, then $\left(x_{n}\right)$ is $d$-Cauchy if and only if $\forall \epsilon>o$ there exists $\mathcal{N}(\epsilon)$ such that $x_{n}+x_{m}<\epsilon$ for $n \geq m \geq \mathscr{N}(\epsilon)$. This implies that $\lim x_{n}=0$. 
However, if $\lim x_{n}=0$, then $\forall \epsilon>0 \exists \mathscr{N}(\epsilon)$, such that $x_{n}<\epsilon / 2$ for $m \geq \mathcal{N}(\epsilon), n \geq \mathcal{N}(\epsilon)$.

Hence $x_{n}+x_{m}<\epsilon$ for $m \geq \mathcal{N}(\epsilon), n \geq \mathscr{N}(\epsilon)$. However, constant sequences are not $d$-Cauchy but $\rho$-Cauchy.

Theorem 13. Let $(X, d)$ be a metric space, $\rho$ the metric associated with $d$ on $X,\left(X^{*}, d^{*}\right)$ the completion of $(X, d)$, and $\rho^{*}$ the metric associated with $d^{*}$ on $X^{*}$. Then $\left(X^{*}, \rho^{*}\right)$ is the completion of $(X, \rho)$. In particular if $(X, d)$ is a complete metric space then $(X, \rho)$ is a complete metric space. We prove that

(i) $X$ is dense in $\left(X^{*}, \rho^{*}\right)$;

(ii) every $\rho^{*}$-Cauchy sequence in $X^{*}$ is $\rho^{*}$-convergent.

Proof of $(i)$. Let $x^{*} \in X^{*}-X$. Then there exists a sequence $\left(x_{n}\right)$ in $X$ such that $\lim d^{*}\left(x_{n}^{*}, x^{*}\right)=0$ since $x_{n} \in X, x_{n} \neq x^{*} \forall n$. So that $\lim \rho^{*}\left(x_{n}^{*}, x^{*}\right)=0$.

This implies that $X$ is dense in $\left(X^{*}, \rho^{*}\right)$.

Proof of (ii). Let $\left(x_{n}^{*}\right)$ be $\rho^{*}$-Cauchy in $X^{*}$. If $\left(x_{n}^{*}\right)$ is eventually constant, then there exist $N$ and $x^{*} \in X^{*}$ such that $x_{n}^{*}=x^{*}$ for $n \geq N$.

In this case $\lim \rho^{*}\left(x_{n}^{*}, x^{*}\right)=0$ for $n \geq N$; hence $\left(x_{n}^{*}\right)$ is $\rho^{*}$-convergent.

Suppose $\left(x_{n}^{*}\right)$ is not eventually constant. Then $\left(x_{n}^{*}\right)$ is a $d^{*}$-Cauchy sequence. Since $\left(X^{*}, d^{*}\right)$ is complete, there exists $x^{*} \in X^{*}$ such that $\lim d^{*}\left(x_{n}^{*}, x^{*}\right)=0$. Since $0 \leq \rho^{*}\left(x_{n}^{*}, x^{*}\right) \leq$ $d^{*}\left(x_{n}^{*}, x^{*}\right)=0, \lim \rho^{*}\left(x_{n}^{*}, x^{*}\right)=0$.

Hence $\left(x_{n}^{*}\right)$ is $\rho^{*}$-convergent to $x^{*}$. This completes the proof of (ii).

\section{Disclosure}

I. Ramabhadra Sarma is a retired professor from Acharya Nagarjuna University, Andhra Pradesh, India.

\section{Conflict of Interests}

The authors declare that there is no conflict of interests regarding the publication of this paper.

\section{Acknowledgments}

The authors thank the editor and anonymous referees for their constructive comments and ideas which helped us to improve the paper.

\section{References}

[1] L. F. McAuley, "A relation between perfect separability, completeness, and normality in semi-metric spaces," Pacific Journal of Mathematics, vol. 6, pp. 315-326, 1956.

[2] R. L. Moore, Foundations of Point Set Theory: American Mathematical Society Colloquium Publications, vol. 13, Literary Licensing, LLC, New York, NY, USA, 1932.

[3] S. P. Moshokoa, "On completeness in symmetric spaces," Quaestiones Mathematicae, vol. 30, no. 1, pp. 13-20, 2007.
[4] P. Hitzler, Generalized metrics and topology in logic programming semantics [Ph. D. thesis], School of Mathematics, Applied Mathematics and Statistics, National University Ireland, University College Cork, 2001.

[5] C. T. Aage and J. N. Salunke, "The results on fixed points in dislocated and dislocated quasi-metric space," Applied Mathematical Sciences, vol. 2, no. 59, pp. 2941-2948, 2008.

[6] E. Karapınar and P. Salimi, "Dislocated metric space to metric spaces with some fixed point theorems," Fixed Point Theory and Applications, vol. 2013, article 222, 2013.

[7] P. S. Kumari, V. V. Kumar, and I. R. Sarma, "Common fixed point theorems on weakly compatible maps on dislocated metric spaces," Mathematical Sciences, vol. 6, article 71, 2012.

[8] P. S. Kumari, “On dislocated quasi metrics," Journal of Advanced Studies in Topology, vol. 3, no. 2, pp. 66-74, 2012.

[9] P. S. Kumari, V. V. Kumar, and R. Sarma, "New version for Hardy and Rogers type mapping in dislocated metric space," International Journal of Basic and Applied Sciences, vol. 1, no. 4, pp. 609-617, 2012.

[10] I. R. Sarma and P. S. Kumari, "On dislocated metric spaces," International Journal of Mathematical Archive, vol. 3, no. 1, pp. 72-77, 2012.

[11] I. R. Sarma, J. M. Rao, P. S. Kumari, and D. Panthi, "Convergence axioms on dislocated symmetric spaces," Abstract and Applied Analysis, vol. 2014, Article ID 745031, 7 pages, 2014.

[12] P. Sumati Kumari, Ch. V. Ramana, and K. Zoto, "On quasisymmetric space," Indian Journal of Science and Technology, vol. 7, no. 10, pp. 1583-1587, 2014.

[13] P. S. Kumari, "Fixed and periodic point theory in certain spaces," Journal of the Egyptian Mathematical Society, vol. 21, no. 3, pp. 276-280, 2013.

[14] M. Imdad, J. Ali, and L. Khan, "Coincidence and fixed points in symmetric spaces under strict contractions," Journal of Mathematical Analysis and Applications, vol. 320, no. 1, pp. 352360, 2006.

[15] S.-H. Cho, G.-Y. Lee, and J.-S. Bae, "On coincidence and fixedpoint theorems in symmetric spaces," Fixed Point Theory and Applications, vol. 2008, Article ID 562130, 9 pages, 2008. 


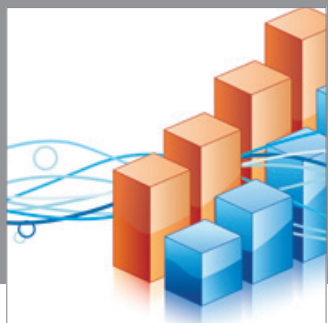

Advances in

Operations Research

mansans

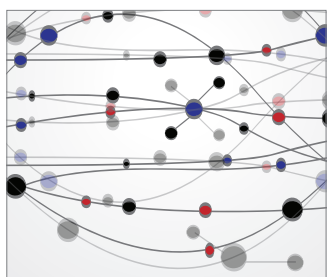

The Scientific World Journal
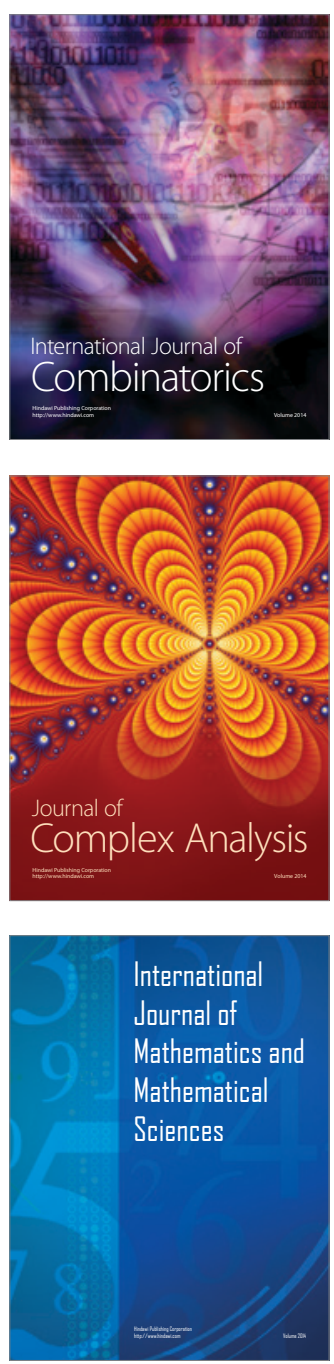
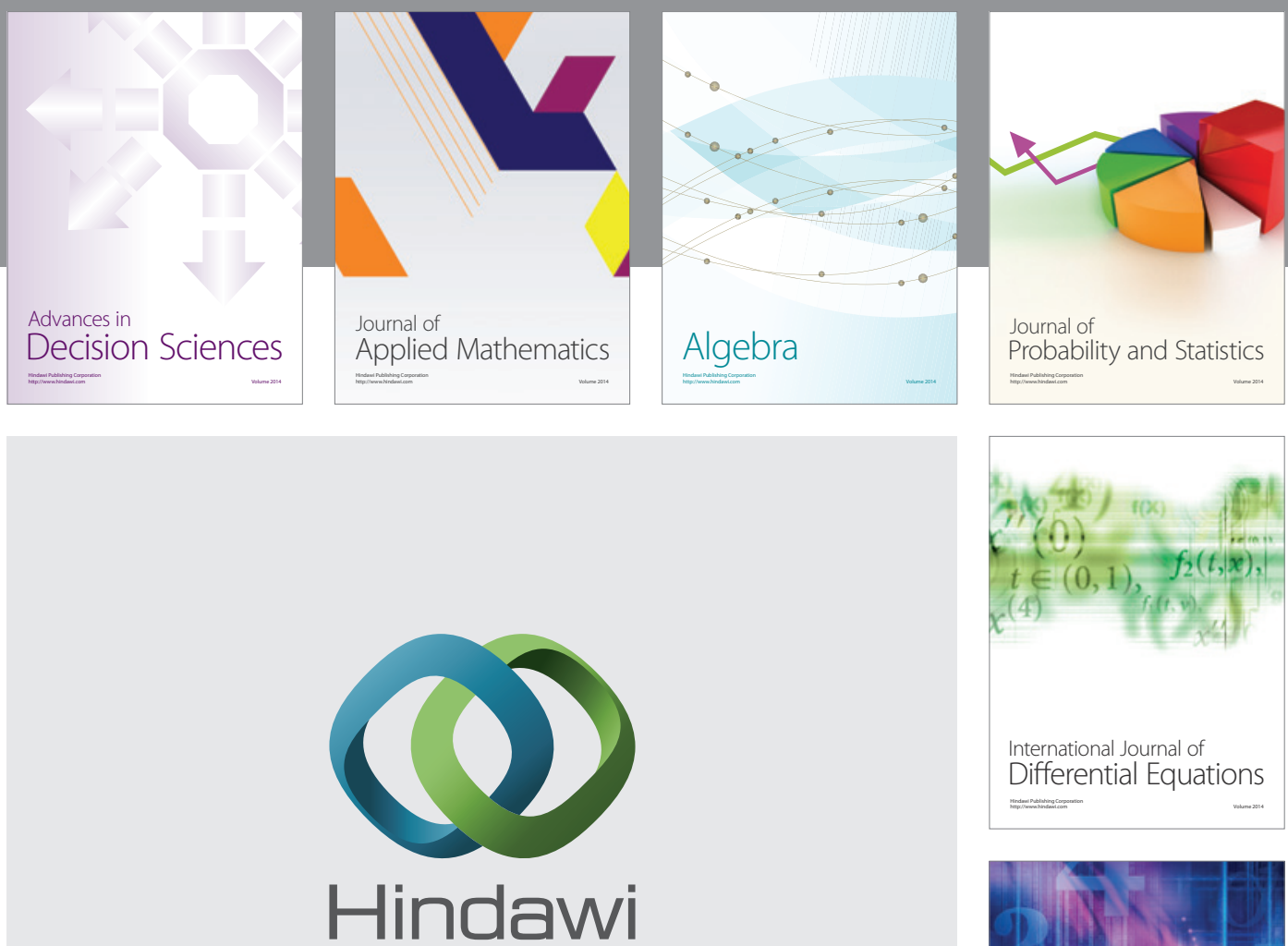

Submit your manuscripts at http://www.hindawi.com
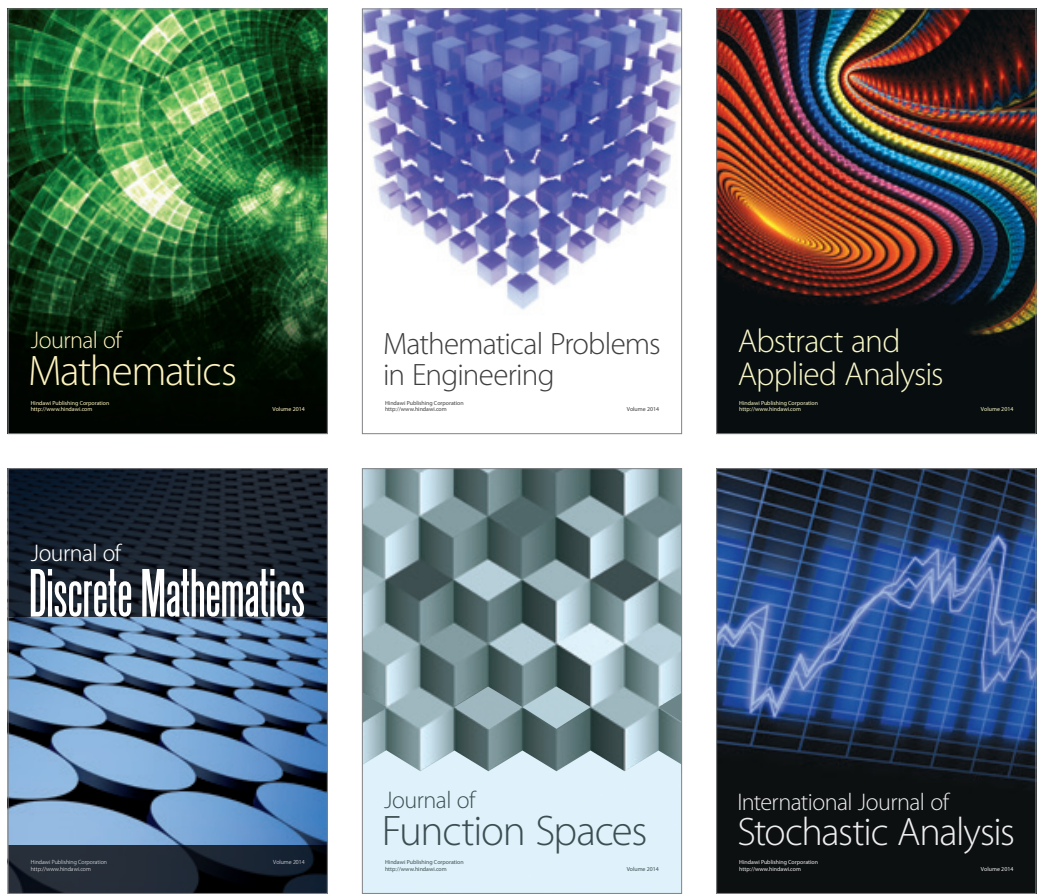

Journal of

Function Spaces

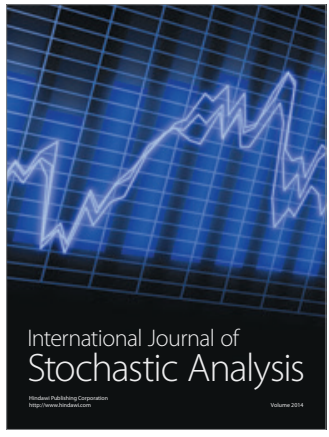

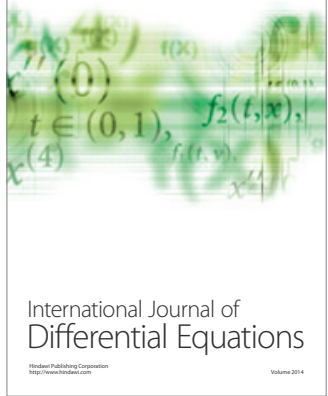
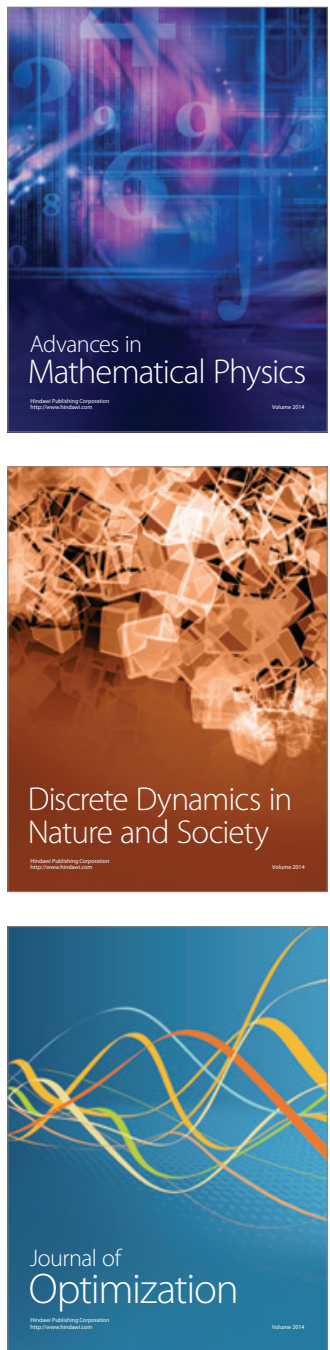